\title{
Feasibility of Using High-Performance Steel Fibre Reinforced Concrete for Simplifying Reinforcement Details of Critical Members
}

\author{
Seok-Joon Jang, ${ }^{1}$ Dae-Hyun Kang, ${ }^{1}$ Kyung-Lim Ahn, ${ }^{1}$ Wan-Shin Park, ${ }^{2}$ \\ Sun-Woong Kim, ${ }^{2}$ and Hyun-Do Yun ${ }^{1}$ \\ ${ }^{1}$ Department of Architectural Engineering, Chungnam National University, Daejeon 305-764, Republic of Korea \\ ${ }^{2}$ Department of Construction Engineering Education, Chungnam National University, Daejeon 305-764, Republic of Korea
}

Correspondence should be addressed to Hyun-Do Yun; wiseroad@cnu.ac.kr

Received 26 July 2015; Accepted 27 September 2015

Academic Editor: João M. L. Dos Reis

Copyright @ 2015 Seok-Joon Jang et al. This is an open access article distributed under the Creative Commons Attribution License, which permits unrestricted use, distribution, and reproduction in any medium, provided the original work is properly cited.

\begin{abstract}
This paper addresses the effects of hooked-end steel fibre contents on the mechanical properties of high-performance concrete (HPC) and investigates the feasibility of utilizing steel fibres to simplify the complicated reinforcement detailing of critical HPC members under high shear stress. Mechanical properties of HPCs with specified compressive strength of 60 and $100 \mathrm{MPa}$ include the flow, air content, compressive strength, and flexural strength. The effectiveness of $1.50 \%$ steel fibre content on the shear behaviour of diagonally reinforced concrete coupling beam without additional transverse reinforcement was investigated to alleviate complex reinforcing details for the full section confinement of diagonal bar groups. The test results revealed the incorporation of steel fibres significantly affected the mechanical properties of the HPCs. For diagonally reinforced coupling beam (SFRCCB) without additional transverse reinforcement, the addition of $1.5 \%$ steel fibre content into $60 \mathrm{MPa}$ HPC coupling beam provides similar cracking and structural behaviours compared to those of diagonally reinforced coupling beam (CCB) with full section confinement details. However, the ductility of SFRCCB was less than that of CCB. It is recommended that both stirrups and steel fibre should be used for fully confining the diagonal bar groups of coupling beams to achieve the ductile behaviour.
\end{abstract}

\section{Introduction}

Steel fibrous concrete is a composite material that contains randomly distributed steel fibres in the conventional concrete with the brittle nature. The inclusion of steel fibres significantly improves the tensile strength, postcracking characteristics, and toughness of concrete due to the crack-bridging of added steel fibres. Over the last 40 years, extensive efforts have been devoted to investigate the effects of the incorporation of steel fibres on the mechanical properties of normal-strength concrete [1] as well as the effectiveness of steel fibres as shear reinforcement in the structural elements [2-4].

To investigate the effect of steel fibres on the shear behaviour of reinforced concrete (RC) beams, Narayanan and Darwish [2] carried out 33 shear tests on simply supported rectangular beams with crimped steel fibres as web reinforcement. It was reported that the crack patterns of steel fibre reinforced concrete (SFRC) beams were similar to those shown in the RC beams with conventional stirrups; the ultimate shear strength of RC beam with $1 \%$ crimped steel fibres also exhibited equivalent strengths obtained from RC beam with shear stirrups due to the improvement in dowel action and arch action resulting from the inclusion of steel fibres. Even after their study, in order to improve the shear performance of shear-dominant RC beam, the enhancement of brittle behaviour of conventional concrete in diagonal tension by adding steel fibres has been proposed and investigated over the last decades [5-11].

The replacement of transverse reinforcement with steel fibres in the RC beams was first tried at the early 1970s. Then, a dozen studies have been presented [3, 4, 9, 12-18]. Batson et al. [12] reported first that steel fibres were feasible to replace transverse reinforcements in conventional RC beams. Swamy and Bahia [13] showed that steel fibres control 
the dowel cracking, deflection, strains, and rotation due to shear loads. The effectiveness of both steel and synthetic fibres of various kinds was investigated by Li et al. [9]. Their work demonstrated that the improvement of tensile performance in the concrete through fibre reinforcements can be translated into shear performance enhancement. The results obtained by Casanova and Rossi [3] showed that the replacement of transverse reinforcements in $90 \mathrm{MPa}$ high-strength concrete (HSC) beams with $1.25 \%$ steel fibres could obtain equivalent performances of HSC beams with $1.1 \%$ conventional transverse reinforcements. Cucchiara et al. [4] conducted experimental tests on the hooked-end SFRC beams with different amount of shear reinforcement, shearto-span ratio, and fibre volume fraction. Their test results indicated that the addition of hooked-end steel fibres in the shear-dominant RC beams can transform the brittle behaviour characterized by shear failure into a ductile one by flexural failure. These results confirmed the feasibility of using steel fibres instead of increasing the amount of shear reinforcement for $40 \mathrm{MPa}$ normal-strength concrete (NSC) beams. The use of steel fibres as shear as well as torsional reinforcement was also studied to examine the effectiveness of fibres as a potential replacement of conventional stirrups [14]. It is reported that the fibrous concrete beams exhibited improved torsional performance compared with the corresponding conventional concrete beams. Recently, Minelli and Plizzari [16] showed that a relatively low amount, less than $0.7 \%$, of steel fibres could remarkably improve the shear strength and ductility of concrete beams without transverse reinforcement. Chalioris [19] investigated the effect of steel fibres in shear-dominant reinforced concrete beams under cyclic loadings. His tests indicated that not only do steel fibres inhibit the development of cracking (crack propagation and crack width grow) but they also prevent cracks from closing during the reversal loading. Further, SFRC proved to be capable of supporting cyclic loading conditions exhibiting greater energy dissipation capacities with respect to the plain concrete.

Despite extensive laboratory demonstrations on usefulness of fibres in various structural applications, the practical application of fibres in construction industries is limited. Limited information on the design methods and specifications makes it difficult for the engineers to use SFRC for structural elements in the buildings and infrastructures. If the required shear force of a reinforced concrete beam is not greater than half of design shear strength provided by concrete, the replacement of the conventional shear reinforcement with deformed steel fibres was allowed in the ACI 318-08 [20]. The addition of deformed steel fibre should be more than $0.75 \%$ at fibre volume fraction and compressive strength of SFRC does not exceed $42 \mathrm{MPa}$. SFRC shall be satisfied with the flexural performance criteria as described in ACI 318-08 S5.6.6. Jain and Singh [18] investigated the validity of flexural performance criteria in the SFRC recommended in the ACI 318-08 for replacing minimum shear reinforcement with deformed steel fibres. They reported that an allowable shear stress value of $0.3 \sqrt{ } f_{c}^{\prime} \mathrm{MPa}$ is for being reinforced with the deformed steel fibres instead of transverse reinforcement in the NSC and HSC beams.
The large amount of experimental studies conducted in this sector has been concentrated on shear strength and crack patterns of fibrous NSC beams subjected to monotonic loading. A limited amount of research has focused on the hysteretic behaviours of shear-dominant RC beams incorporating steel fibres instead of conventional transverse reinforcements under reversed cyclic loading.

Recently, social needs for high-rise buildings and large infrastructures lead to an urgent development for higher performance engineering materials possessing high strength, toughness, energy dissipation capacity, durability, and so forth. High-performance steel fibre reinforced concrete (HPSFRC) is a kind of HPC which has made noticeable advances during last decades. However, very limited research work on mechanical performances and applications of HP-SFRC with different fibre volume fractions and compressive strengths has been conducted so far.

In this study, the influence of steel fibre contents on the mechanical properties of high-performance concrete (HPC) is first experimentally investigated. The flexural performance of high-performance steel fibre reinforced concrete (HPSFRC) with different fibre volume fractions was evaluated in accordance with ASTM C 1609. The experimental programme also includes the tests on shear-dominant diagonally reinforced concrete coupling beams with and without transverse reinforcement specified in the ACI 318-11 Section 21. The use of hooked-end steel fibres as replacement of transverse reinforcement in the short coupling beam with diagonal reinforcement is investigated herein, in an attempt to simplify the placement of reinforcing bars and reduce congestion without sacrificing shear strength, ductility, and energy absorption capacity under reversed cyclic loading.

\section{Mechanical Properties of High-Performance Steel Fibre Reinforced Concretes (HP-SFRCs)}

The influence of steel fibres on the mechanical properties of high-performance concretes (HPCs) with specific compressive strengths of 60 and $100 \mathrm{MPa}$ was investigated in this study. This section describes the experimental programme, such as materials used, mix proportion and mixing, test method, and fresh and hardened properties, carried out to examine the effect of adding steel fibres on the mechanical properties of HPC.

2.1. Materials. In this study, HP-SFRCs were mixed using hooked-end steel fibres, fine aggregate, coarse aggregate, and cement paste. The cement paste consists of ordinary Portland cement (OPC), water, superplasticizer, and silica fume. Ordinary Portland cement conforming to Korean Industrial Standard (KS), KS L 5201, was used for the cement pastes. Silica fume was a commercially available product and was used for only $100 \mathrm{MPa}$ high-performance concrete mixtures. A polycarbonate based superplasticizer was added to improve the workability of concretes. River sand with a fineness modulus of 3.1 and crushed aggregate of $13 \mathrm{~mm}$ maximum size were used and obtained from a local supplier. Steel fibres 
TABLE 1: Mixture proportions of HPCs used in the study.

\begin{tabular}{|c|c|c|c|c|c|c|c|c|c|c|c|}
\hline \multirow{2}{*}{ Mix notation } & \multirow{2}{*}{$f_{c}^{\prime}(\mathrm{MPa})$} & \multirow{2}{*}{$V_{f}(\%)$} & \multicolumn{9}{|c|}{ Unit weight $\left(\mathrm{kg} / \mathrm{m}^{3}\right)$} \\
\hline & & & Cement & Water & Aggregate & Sand & FA & SF & Fibres & SP & $\mathrm{AE}$ \\
\hline 06-SFRC00 & 60 & 0.0 & 662 & 199 & 537 & 894 & 0 & 0 & 0 & 3.97 & 1.32 \\
\hline 06-SFRC05 & & 0.5 & & & & & & & 39 & & \\
\hline 06-SFRC10 & & 1.0 & & & & & & & 79 & & \\
\hline 06-SFRC15 & & 1.5 & & & & & & & 118 & & \\
\hline 10-SFRC00 & 100 & 0.0 & 583 & 150 & 816 & 570 & 183 & 67 & 0 & 10.46 & 0 \\
\hline 10-SFRC05 & & 0.5 & & & & & & & 39 & & \\
\hline 10-SFRC10 & & 1.0 & & & & & & & 79 & 11.63 & \\
\hline 10-SFRC15 & & 1.5 & & & & & & & 118 & 11.49 & \\
\hline
\end{tabular}

$f_{c}^{\prime}$ is a specific compressive strength of HPC; $V_{f}$ is steel fibre volume fraction; FA is fly ash; SF is silica fume; SP is superplasticizer; AE is air entraining reagent.

TABLE 2: Mechanical properties of HPCs used in the study.

\begin{tabular}{|c|c|c|c|c|c|c|}
\hline \multirow[b]{2}{*}{ Mix notation } & \multirow[b]{2}{*}{$\begin{array}{l}\text { Air content } \\
(\%)\end{array}$} & \multirow[b]{2}{*}{$\begin{array}{l}\text { Slump } \\
(\mathrm{mm})\end{array}$} & \multicolumn{2}{|c|}{ Compressive strength (MPa) } & \multicolumn{2}{|c|}{ Flexural strength (MPa) } \\
\hline & & & $\begin{array}{c}28 \text { days } \\
(\text { mean } \pm \mathrm{SD})\end{array}$ & $\begin{array}{c}90 \text { days } \\
(\text { mean } \pm S D)\end{array}$ & $\begin{array}{c}28 \text { days } \\
(\text { mean } \pm \text { SD) }\end{array}$ & $\begin{array}{c}90 \text { days } \\
(\text { mean } \pm \text { SD) }\end{array}$ \\
\hline 06-SFRC00 & 2.5 & 270 & $67.0 \pm 0.6$ & $73.1 \pm 0.6$ & $11.1 \pm 0.5$ & - \\
\hline 06-SFRC05 & 2.7 & 240 & $64.7 \pm 0.4$ & $72.5 \pm 2.0$ & $11.0 \pm 0.7$ & - \\
\hline 06-SFRC10 & 3.5 & 225 & $64.2 \pm 0.1$ & $73.7 \pm 2.3$ & $11.2 \pm 0.2$ & - \\
\hline 06-SFRC15 & 3.8 & 185 & $64.3 \pm 0.2$ & $71.4 \pm 0.9$ & $15.8 \pm 0.4$ & - \\
\hline 10-SFRC00 & 1.1 & 500 & $79.1 \pm 3.6$ & $111.9 \pm 1.1$ & - & $14.0 \pm 0.8$ \\
\hline 10-SFRC05 & 1.2 & 205 & $82.5 \pm 0.0$ & $107.8 \pm 0.9$ & - & $15.1 \pm 0.3$ \\
\hline 10-SFRC10 & 1.7 & 175 & $88.5 \pm 2.5$ & $110.0 \pm 0.1$ & - & $15.9 \pm 1.6$ \\
\hline 10-SFRC15 & 2.0 & 150 & $87.1 \pm 4.7$ & $108.7 \pm 2.6$ & - & $18.2 \pm 1.0$ \\
\hline
\end{tabular}

Each strength is an average of strengths from three specimens; SD is standard deviation.

used in this investigation were hooked-end bundled fibres with aspect ratio ( $l / d$; length over diameter ratio) of 60 . The average fibre length is $30 \mathrm{~mm}$, the nominal diameter is $0.5 \mathrm{~mm}$, and the tensile strength is $1,100 \mathrm{MPa}$.

2.2. Mix Proportion and Mixing. The matrix compositions for HPCs were presented in Table 1 in this experiment. Each mixture was chosen to cover the parameters discussed in the experimental programme. The volume fractions of steel fibre in the HPC mixes with specific compressive strength of 60 and $100 \mathrm{MPa}$ were $0,0.5,1.0$, and $1.5 \%$, respectively. In order to obtain the desired workability, only the superplasticizer dosage was varied. As described above, silica fume and fly ash were used for only $100 \mathrm{MPa}$ HPC.

For the production of HP-SFRCs, the cementitious constituents, such as coarse aggregate, river sand, cement, and silica fume, were initially mixed dry in twin shaft mixer of $1 \mathrm{~m}^{3} / \mathrm{h}$ capacity. The superplasticizer was then diluted with the mixing water and added to the mixer. Fibres were dispersed by hand in small amounts into cement paste to avoid fibre balling and to achieve a uniform material consistency and good workability. For mixes with 1.5\% fibre content, extra time was required for mixing and finishing the specimen surfaces. Fresh HP-SFRCs were cast into 100 $\times 200 \mathrm{~mm}$ cylindrical moulds for a compressive strength test and into $100 \times 100 \times 400 \mathrm{~mm}$ prismatic moulds for flexural strength test. The specimens were demoulded after $24 \mathrm{~h}$ and cured in a water tank until the age of testing. And then a strength test was carried out.

2.3. Test Methods. The workability of fresh HP-SFRC was assessed by using slump test according to KS F 2402. Air content was measured by using the pressure method in accordance with KS F 2409.

The compressive strength tests for cylindrical specimens at the curing age of 3,7 , and 28 days were carried out with a universal testing machine of capacity of $1,000 \mathrm{kN}$ at a loading rate of $0.3 \mathrm{MPa} / \mathrm{s}$. The flexural strength (modulus of rupture, MOR) tests were performed using prismatic specimens under four-point loading. The average mid-span deflection was measured with two transducers placed at the centre of the prismatic specimens. The compressive and flexural strength tests were conducted in accordance with KS F 2405 and KS F 2407 , respectively.

2.4. Fresh Properties of HP-SFRC. Slump value workability and entrapped air content measurement were carried out on the fresh high-performance steel fibre reinforced concrete. The results are presented in Table 2 . The results showed that air contents of $60 \mathrm{MPa}$ HP-SFRCs decreased gradually with the increase of steel fibre content. The randomly distributed hooked-end steel fibre could possibly form air bubbles thus increasing the percentage of entrapped air. On the other hand, the air contents of $100 \mathrm{MPa}$ HP-SFRCs with different amount 


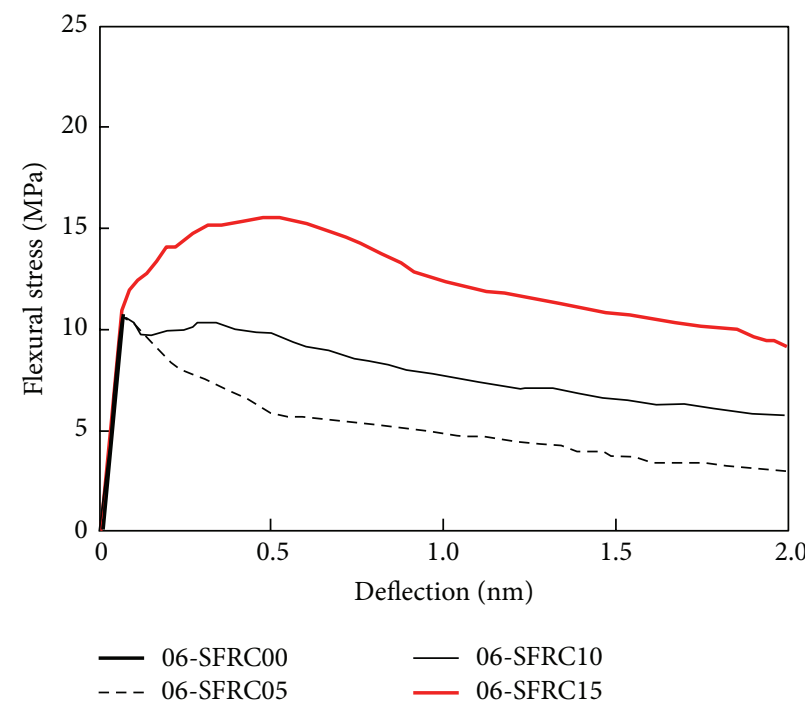

(a) 06 -SFRC series at 28 days

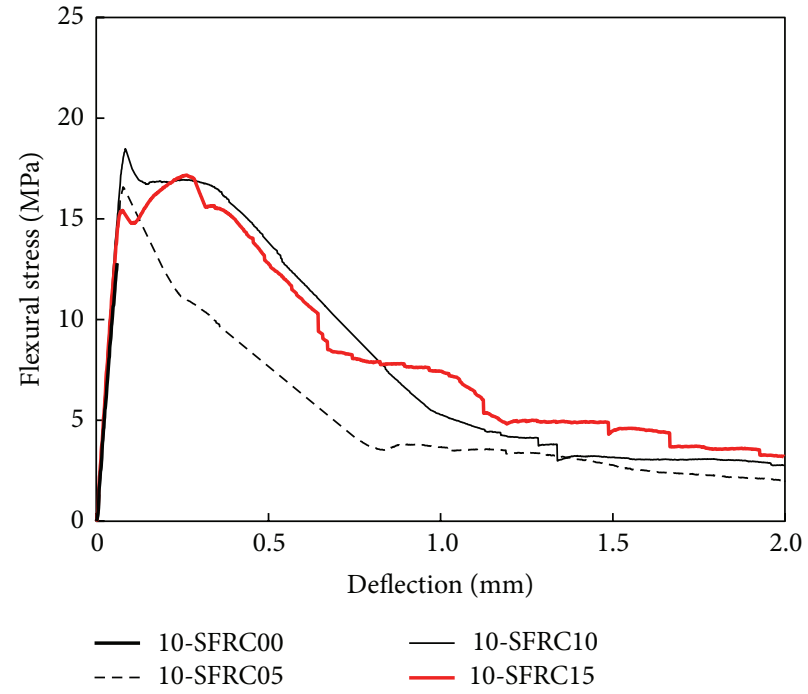

(b) 10-SFRC series at 90 days

FIGURE 1: Typical load-deflection curves of HP-SFRC prisms.

of SP were in the range from $1.1 \%$ to $2.0 \%$ and did not show a clear trend like that of $60 \mathrm{MPa}$ SFRC. The air contents of $60 \mathrm{MPa}$ SFRCs were higher than those of $100 \mathrm{MPa}$ SFRCs due to the AE admixture added to only $60 \mathrm{MPa}$ SFRCs.

To estimate the workability of the fresh HP-SFRC according to steel fibre volume fraction, slump values for all the HP-SFRC mixes were measured. In both 60 and $100 \mathrm{MPa}$ SFRCs, as steel fibre volume percentage increases, the slump values decrease in all HP-SFRC mixtures as reported by existing studies [21-24]. In plain concrete mix with specific compressive strength of $100 \mathrm{MPa}$, the highest slump value was obtained because the incorporation of fly ash with spherical shape as cement replacement leads to the ball bearing effects in fresh concrete [22]. However, as the steel fibre volume fraction increases, the slump value in the $100 \mathrm{MPa}$ HP-SFRC mixes reduced more remarkably than that in the $60 \mathrm{MPa} \mathrm{HP}-$ SFRCs.

2.5. Hardened Properties of HP-SFRC. The results for the compressive and flexural strength of all mixture at curing ages of 28 and 90 days are presented in Table 2. From the results for compressive strength, it is evident that the compressive strength of plain concrete with 60 and $100 \mathrm{MPa}$ mixed in this study exceeded that obtained from varying volume percentage of hooked-end steel fibres. Similar result was reported also by other researchers [22]. Table 2 provided that, for HP-SFRC mixes with specific compressive strength of $60 \mathrm{MPa}$, the target compressive strengths could be gained at curing age of 28 days while the target strength for $100 \mathrm{MPa}$ HP-SFRCs could be reached at curing age of 90 days.

The flexural strength and performance were evaluated according to ASTM C 1609 procedure. The measured load versus mid-span deflection curves of the $60 \mathrm{MPa}$ HP-SFRC prisms at 28 days and $100 \mathrm{MPa}$ HP-SFRC prisms at 90 days are shown in Figures 1(a) and 1(b), respectively. Figure 1(a) indicates that the incorporation of steel fibre volume ranging from $0.0 \%$ to $1.0 \%$ in the $60 \mathrm{MPa}$ SFRCs (06-SFRC00, 05 and 10) had little effect on the modulus of rupture of the prism specimens but significantly improved the postcracking behaviour. The load-deflection curve of $60 \mathrm{MPa}$ SFRC (06SFRC15) prisms with $1.5 \%$ fibre volume fraction showed a plateau before the applied load started to decrease. As shown in Figure 1(b), the flexural strength of 10-SFRC mix series improved with increasing of the fibre volume fraction. The enhancement of flexural strength started from $7.9 \%$ at $0.5 \%$ fraction and expanded to $30 \%$ at $2.0 \%$ fraction. The postcracking behaviours of 10-SFRC10 and 10-SFRC15 prisms are similar.

To evaluate the flexural toughness of hooked-end steel fibre reinforced concretes with different fibre volume fractions, the flexural toughness was calculated according to ASTM C 1609. As shown in Figure 2, flexural toughness $\left(T_{150}^{D}\right)$ is measured with the total area under the load-deflection curve up to a specified deflection, 1/150 of the span length. Therefore, the equivalent flexural strength ratio $\left(R_{T, 150}^{D}\right)$ for evaluating the flexural performance is obtained from the following equation, using first-peak strength $\left(f_{1}\right)$.

Figure 3 shows the flexural performance criteria as described in ACI 318-08 S5.6.6 and fibre volume fraction relationship. Shade area in Figure 3 is the condition satisfying the flexural performance criteria in ACI 318-08 S5.6.6. From Figure 3, it can be recognized that about $1.2 \%$ and $1.5 \%$ hooked-end steel fibre volume fraction for $60 \mathrm{MPa}$ and $100 \mathrm{MPa}$ SFRCs are the replacement level of minimum shear reinforcement, respectively.

\section{Feasibility of Using HP-SFRC as Transverse Reinforcements in Short Coupling Beams}

The seismic design provisions of the current ACI 318-11 prescribe extensive requirements for the design and details 


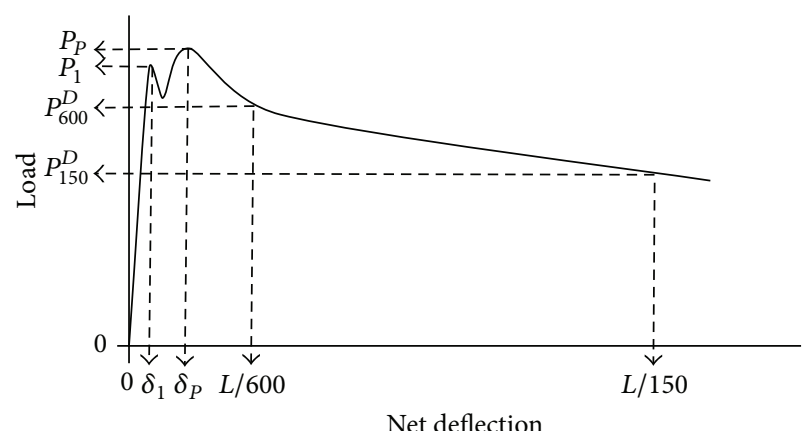

$L$ : span length

$P_{1}$ : first-peak load

$P_{P}$ : peak load

$\delta_{1}$ : net deflection at first-peak load

$\delta_{P}$ : net deflection at peak load

$f_{1}$ : first-peak strength

$f_{P}$ : peak strength

$P_{600}^{D}$ : residual load at net deflection of $L / 600$

$f_{600}^{D}$ : residual strength at net deflection of $L / 600$

$P_{150}^{D}$ : residual load at net deflection of $L / 150$

$f_{150}^{D}$ : residual strength at net deflection of $L / 150$

$T_{150}^{D}$ : area under the load versus net deflection curve 0 to $L / 150$

Figure 2: Flexural toughness defined by ASTM C1609. $R_{T, 150}^{D}=$ $150 T_{150}^{D} / f_{1} b d^{2} \times 100 \%$, where $b$ is the width $(\mathrm{mm})$ of the specimen and $d$ is the height $(\mathrm{mm})$ of the specimen.

of coupling beams in the special reinforced concrete coupled shear wall system. Diagonal reinforcement groups are required for coupling beams having a net span-to-depth ratio $\left(l_{n} / h\right)$ less than 2 and a factored shear stress on the gross concrete section exceeding $0.33 \sqrt{ } f_{c}^{\prime} \mathrm{MPa}$.

It is assumed that the diagonal bar group elements form a truss, with one group acting as the tension member and the other as the compression member for an applied shear load [25]. To suppress premature buckling of the diagonal bar groups, the bars should be confined by transverse reinforcement across the span of the beam to satisfy the same confinement requirements used for tied column. Because these reinforcing details are complex and difficult, ACI 318-08 introduced an alternative detailing option, where transverse reinforcement is placed around the beam cross-section to provide confinement and suppress buckling without transverse bars around the diagonal bar groups. In alternative details of diagonally reinforced coupling beams, stirrup and additional transverse reinforcement such as crosstie and leg bars should be placed closely at spacing not exceeding the smaller of $150 \mathrm{~mm}$ and six times the diameter of diagonal bar [20]. Providing additional transverse reinforcement around the entire cross-section also presents significant difficulties with regard to constructability. The utilization of steel fibre or spiral reinforcement as an alternative of the commonly used stirrup and additional transverse reinforcement can be considered to improve the constructability of short reinforced concrete coupling beams.
In this study, the replacement of the stirrup and additional transverse reinforcement with hooked-end steel fibres is also examined to reduce the construction time and cost for diagonally reinforced concrete coupling beams. The experimental programme includes two short coupling beam tests under reversed cyclic loading. One diagonally reinforced coupling beam (CCB) was manufactured with conventional concrete and alternative details as reference beam. The other beam (SFRCCB) was constructed using $60 \mathrm{MPa}$ HP-SFRC with a fibre volume fraction of $1.5 \%$.

3.1. Test Specimens. To investigate the feasibility of replacing stirrup and additional transverse reinforcement with hookedend steel fibres for the shear-dominant short coupling beams, two specimens were designed, constructed, and tested up to failure. Two diagonally reinforced concrete coupling beam specimens with $l_{n} / h$ of 2.0 have the same configuration and cross-sectional properties and differ in the layouts of the transverse reinforcement. The characteristics of the beams are shown in Figure 4. As shown in Figure 4, the crosssection of all coupling beams was equal to $200 \mathrm{~mm}$ width $\times$ $300 \mathrm{~mm}$ depth. At each end of a coupling beam specimen, a rectangular end block with dimensions of $500 \mathrm{~mm}$ wide $\times 350 \mathrm{~mm}$ deep $\times 1,270 \mathrm{~mm}$ long was used to simulate the surrounding walls and apply the required loading histories.

Conventional concrete coupling beam (CCB) specimen was constructed in accordance with the full section confinement option for diagonally reinforced coupling beams specified in the seismic design provisions of ACI 318-08. Each diagonal bar group consists of eight $10 \mathrm{~mm}$ diameter deformed steel bars. The stirrup and additional transverse reinforcement were placed at $50 \mathrm{~mm}$ spacing of $6 \mathrm{~mm}$ diameter deformed bars around the entire cross-section to satisfy the full section confinement option for CCB specimen. High-performance steel fibre reinforced concrete coupling beam specimen (SFRCCB) is used for a direct comparison with CCB to evaluate the feasibility of replacing transverse crossties and hoop legs with steel fibres. The SFRCCB specimen differs from CCB specimen in that SFRCCB is made with only $60 \mathrm{MPa}$ HP-SFRC instead of stirrup and additional transverse reinforcement in the CCB specimen.

3.2. Testing Setup and Loading Procedure. As shown in Figure 5, diagonally reinforced short coupling beams were tested in a vertical plane with end blocks simulating wall boundary zones at each end. The specimens were subjected to cyclic shear displacement through specially designed strong frame with four pin joints. The strong frame consisted of two steel columns pin-connected with upper loading beam and lower reaction beam. Both end blocks of coupling beam specimen were fully fixed to the upper and lower steel beams of strong frame. Displacements were induced to upper end block of coupling beam by means of an actuator with $1,000 \mathrm{kN}$ capacity connected to the upper steel beam.

Loading histories for coupling beam specimen consist of load-controlled and displacement-controlled cycles. Load control was conducted at 50,100,150, and $200 \mathrm{kN}$. After $200 \mathrm{kN}$, displacement control used increments of percent chord rotation, defined as the relative lateral displacement 


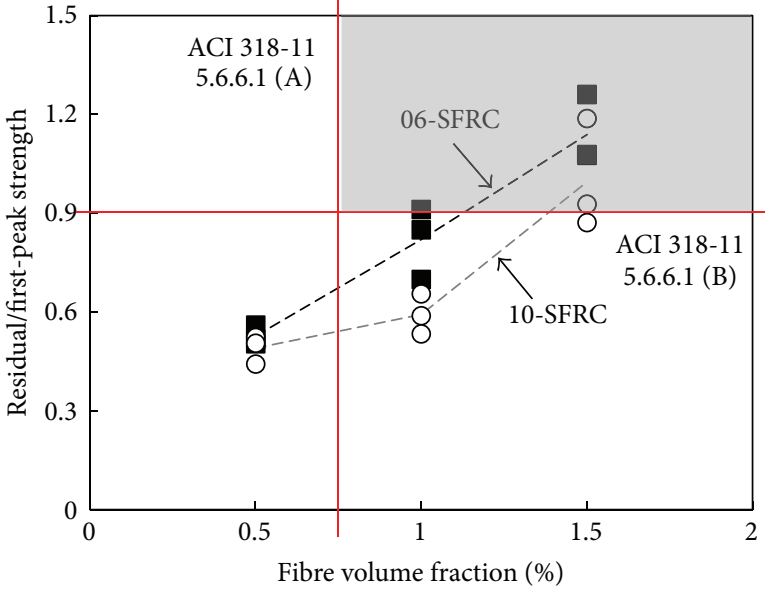

06-SFRC O 10 -SFRC

(a) $1 / 150$

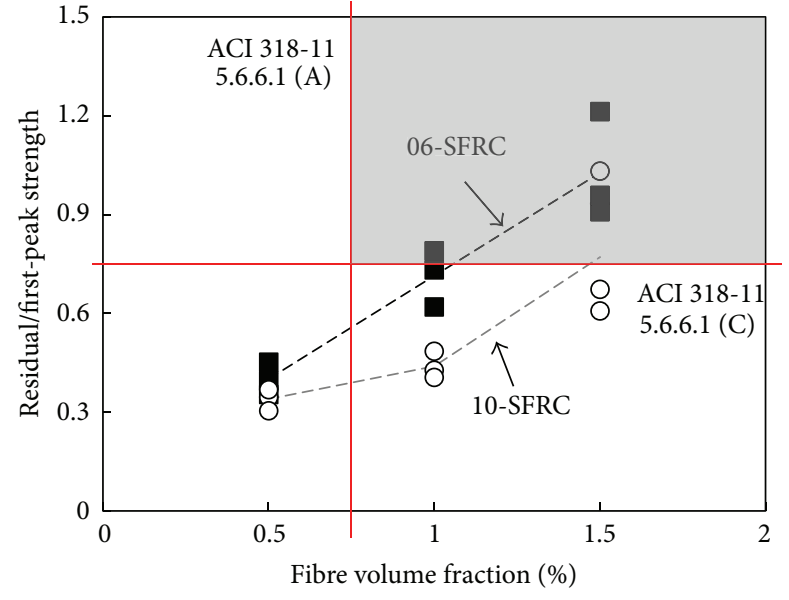

06-SFRC

O $10-$ SFRC

FIGURE 3: Flexural performance of HP-SFRC prisms in accordance with ASTM C 1609.

over the clear span of the coupling beam divided by the beam clear span. Two full cycles were performed at each level of chord rotation up to $5 \%$.

To monitor the external deformations of the coupling beams throughout the test, nine displacement transducers (DTs) were fixed to the surface of specimens. To record the strains developed in the reinforcing steel, strain gauges were mounted on the diagonal, longitudinal, and transverse reinforcement.

3.3. Damage Progress. The cracking process and failure mode of the diagonally reinforced coupling beams differed in accordance with the details of transverse reinforcement. At the beginning of the tests, all the coupling beams showed similar cracking patterns. Cracking patterns at each final cycle of $0.5 \%, 1.0 \%$, and $2.5 \%$ chord rotations for both CCB and SFRCCB beams are shown in Figure 6.

Under the shear load of about $100 \mathrm{kN}$ at load-controlled stage, initial flexural cracks were observed at $100 \mathrm{~mm}$ above the coupling beam-wall joint of CCB specimen. Up to chord rotation of $1.0 \%$, flexure-shear cracks occurred extensively through the beam span. Then, horizontal cracks at the tension edge of interface between beam and wall element appeared and as the chord rotation increased, the horizontal crack propagated into the centre of beam without new cracks on the beam span. The main crack formation had occurred by the end of $2.0 \%$ chord rotation cycle and it consisted of two or three major shear cracks in each loading direction and some flexural cracks at near joints between beam and wall elements. At the chord rotation of $2.5 \%$, the crushing of cover concrete at the edge of compressive region was started. As the loading cycles progressed, the existing flexural cracks widened and cover concrete spalled. At chord rotation of $3.0 \%$ in the negative loading direction, the diagonal reinforcements in compression were buckled and damage was concentrated in the lower region of joint between beam and walls. The CCB specimen failed in concrete spalling at flexure-compressive region.

In SFRCCB specimen, initial cracks occurred at the same loading stage as the CCB specimen. Several flexural cracks were noted at the entire span of the SFRCCB. Up to the chord rotation of $1.0 \%$ as shown in Figure 6, flexural and shear cracks with small width and narrow spacing compared to CCB were observed in the SFRCCB specimen, as the hooked-end steel fibres were effective in bridging these cracks. However, as the applied chord rotation increased up to $1.5 \%$, diagonal cracks widened abruptly. During the second cycle leading to a chord rotation of $2.0 \%$, the SFRCCB specimen experienced a sudden reduction in the lateral loadresisting capacity with increasing significantly the width of diagonal cracks under both direction loadings. This shows that hooked-end steel fibres with length of $30 \mathrm{~mm}$ no longer bridge diagonal cracks at more than $1.5 \%$ chord rotation. In contrast with the flexural-compressive failure of $\mathrm{CCB}$, the failure of SFRCCB was due to the formation of major diagonal cracks, indicating the shear failure. The replacement of transverse reinforcement for full confinement of entire section with hooked-end steel fibres in the shear-dominant coupling beam is effective at less than $1.5 \%$ chord rotation while under the large deformation of more than $1.5 \%$ chord rotation the incorporation of steel fibres cannot entirely replace transverse reinforcement due to the deterioration of fibres' bridging cracks. Similar results in the SFRC beams tested under monotonic loading were reported $[2,4]$.

3.4. Hysteretic Behaviour. The shear force versus chord rotation responses for $\mathrm{CCB}$ and SFRCCB specimens are shown in Figure 6. As shown in Figure 6(a), the CCB with diagonal reinforcements confined fully at the entire crosssection exhibited a large postyield ductile behavior with very limited strength degradation up to a chord rotation of $4.0 \%$ and $2.5 \%$ in the positive and negative loading directions, 


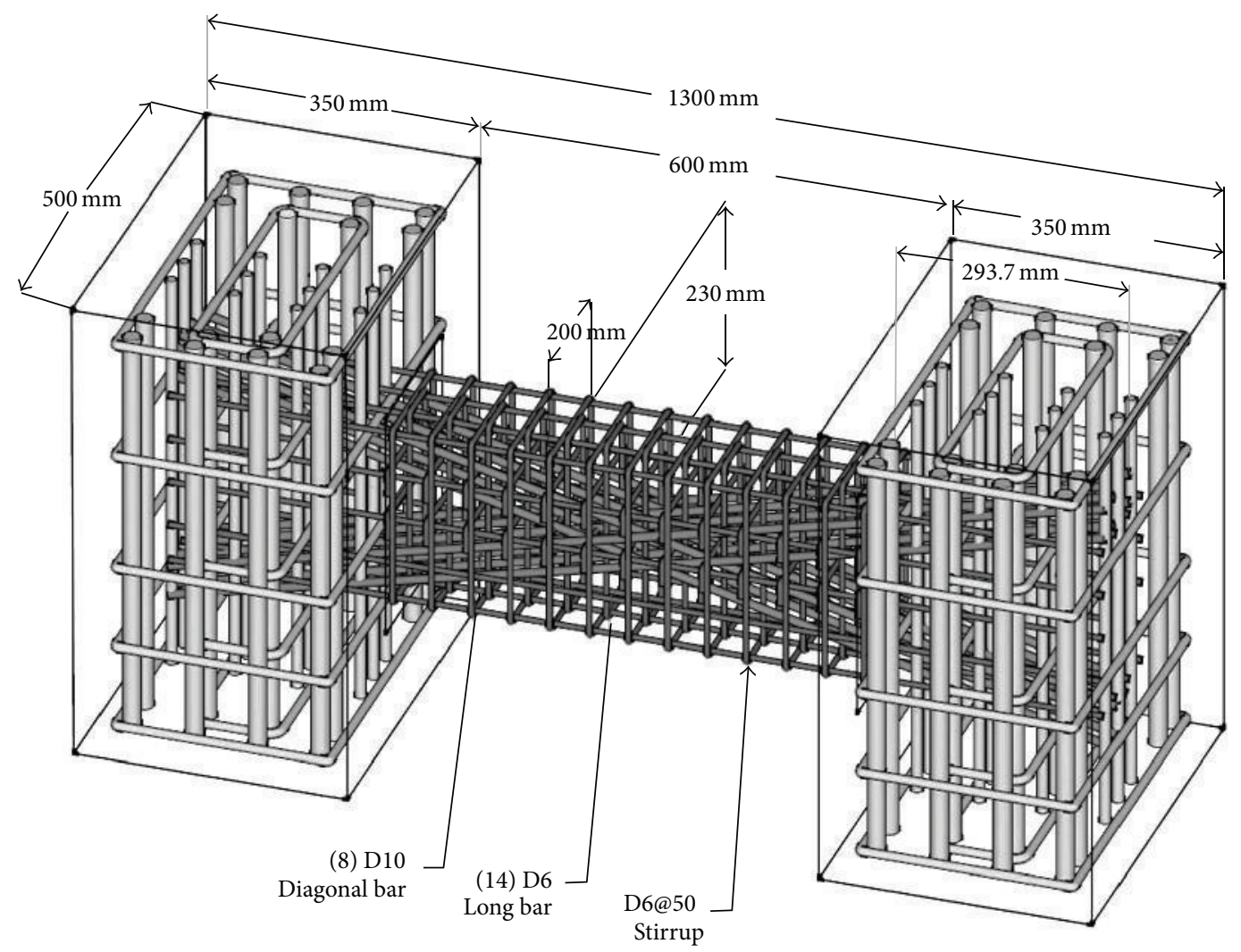

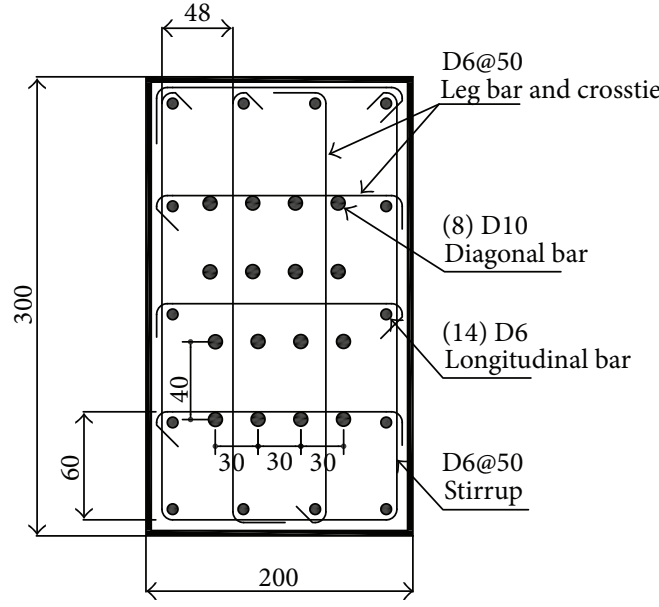

(a)

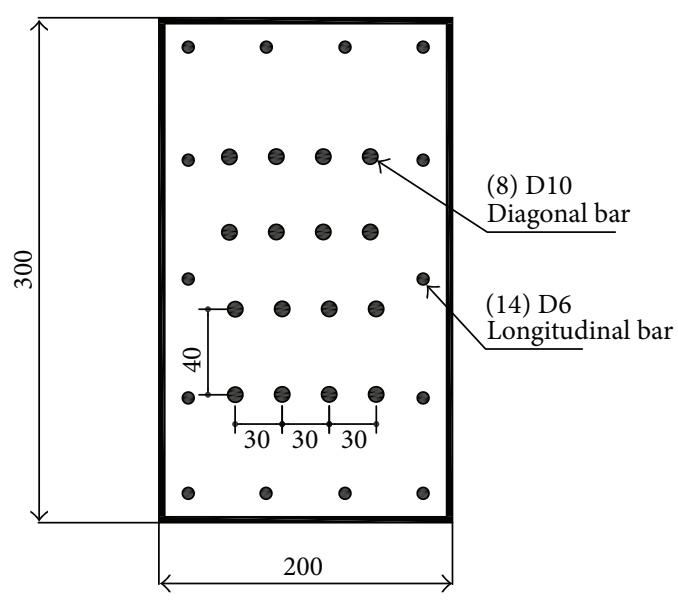

(b)

FIGURE 4: Details of diagonally reinforced coupling beams. (a) CCB specimen. (b) SFRCCB specimen.

respectively. The transverse reinforcement for confining the entire beam cross-section of diagonally reinforced concrete coupling beam as detailed in ACI 318-08, Section S21.9.7, was effective to delay the buckling of diagonal bar bundles in compression up to more than average chord rotation of $3.0 \%$. Naish [26] reported that the hysteretic behaviours of both diagonally reinforced concrete coupling beams with full section confinement and diagonal confinement details were very similar over the full range of applied chord rotations. Through their test results, they concluded that, for diagonally reinforced concrete coupling beams with $l_{n} / h$ of greater than 2.0, the full section confinement provided equivalent performance compared to diagonal confinement.

It is also clear from Figure 6 that SFRCCB shows a reasonably stable response up to $2.0 \%$ chord rotation in both positive and negative loading directions. The SFRCCB specimen exhibited abruptly strength degradation after reaching the peak shear stress at a chord rotation of $2.0 \%$. These results demonstrated that even though the fibre volume fractions satisfying the flexural performance criteria of SFRC in ACI 

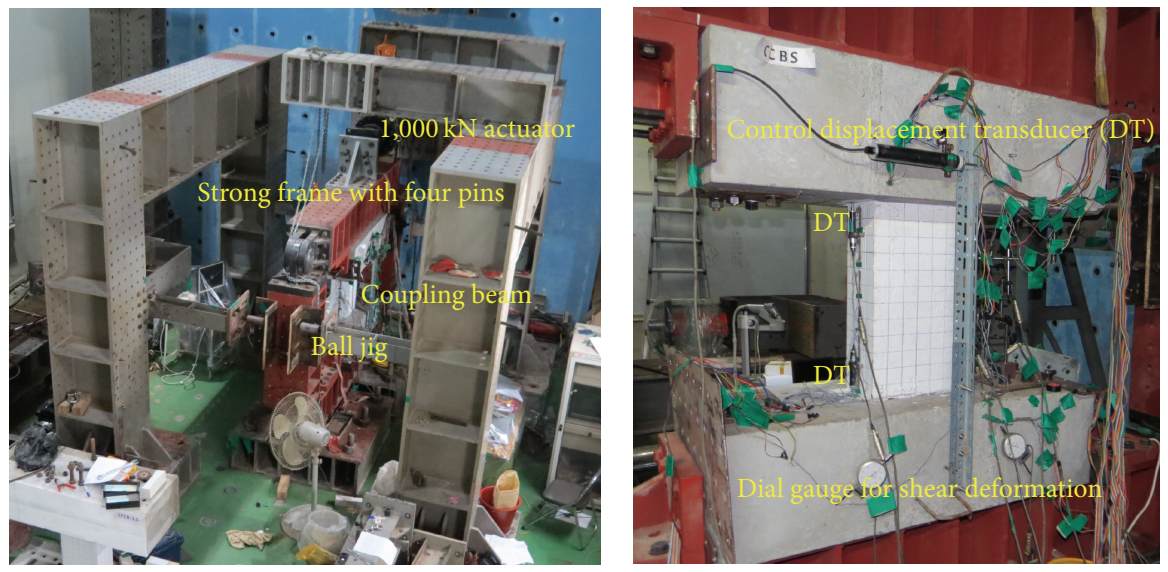

FIGURE 5: Test setup for coupling beams.

318-08 S5.6.6 were effective in controlling cracking opening and confining the diagonal group bars in the diagonally reinforced coupling beams up to a chord rotation of $2.0 \%$, the steel fibre incorporation in the diagonally reinforced coupling beams without transverse reinforcement could not provide appreciable resistance against diagonal shear cracks and buckling of diagonal group bars under large deformation beyond $2.0 \%$ chord rotation. This result is similar to Narayanan and Darwish's conclusion that the steel fibres cannot entirely replace the conventional shear reinforcement when the structural elements are under very high shear stress.

Both CCB and SFRCCB specimens were designed to resist approximately $0.32 \sqrt{ } f_{c k} \mathrm{MPa}$. The average maximum applied shear stress in CCB and SFRCCB was $0.84 \sqrt{ } f_{c u} \mathrm{MPa}$ and $0.82 \sqrt{ } f_{c u} \mathrm{MPa}$, respectively. Even though the transverse reinforcement detailed at entire beam cross-section for confining diagonal bar groups was completely eliminated in the SFRCCB specimen, the shear strength was equivalent to that of the corresponding $\mathrm{CCB}$ with conventional transverse reinforcements for diagonal bars. The similar trends in the SFRC beams without shear reinforcement under monotonic loading also were observed and reported $[4,27]$.

3.5. Average Shear Strains. The average shear strain in the coupling beam specimens was measured using two diagonal dial gauges over coupling beams. Figure 7(a) shows the average shear stress versus shear strain responses for CCB and SFRCCB specimen. Both specimens did not exhibit pinching due to diagonal reinforcement.

Figure 7(b) indicates the average shear strain and chord rotation relationship of conventional concrete and HP-SFRC coupling beams. As shown in Figure 7(b), it is clear that the rate of average shear strain increase in the SFRCCB was less than that in the $\mathrm{CCB}$ specimen. Shear strain in excess of 0.015 and $0.030 \mathrm{rad}$ was recorded in SFRCCB and CCB specimen, respectively. Shear related damage started at shear strain larger than 0.010 and $0.025 \mathrm{rad}$ in the SFRCCB and $\mathrm{CCB}$, respectively. These shear strains can be considered as the shear distortion capacity of the coupling beams with different transverse reinforcing method for diagonal reinforcement group, only hooked-end steel fibre without stirrup and conventional transverse reinforcements. As shown in Figure 6, more fine cracks in the SFRCCB were observed and the crack width was well controlled compared with CCB specimen up to $1.5 \%$ chord rotation due to fibre-bridging action. Up to $1.5 \%$ chord rotation, the steel fibres' bridging diagonal cracks in the SFRCCB specimen contributed to the reduction of the shear distortion. At more than $1.5 \%$ chord rotation in the SFRCCB without transverse reinforcements, the pullout and breaking of fibres bridging diagonal cracks led to abrupt strength reduction and diagonal shear failure.

3.6. Strain in the Diagonal Reinforcements. Figures 8(a) and 8(b) show the strain-chord rotation histories obtained from strain gauges placed on the diagonal reinforcement and located at the centre of CCB and SFRCCB specimens, respectively. There was substantial difference in the strain histories for diagonal bar in the CCB specimen with full section confinement compared with SFRCCB specimen incorporating hooked-end steel fibres instead of transverse confining reinforcement.

In CCB specimen, tensile strains in the diagonal bars increased as the test progressed while compressive strains did not increase and remained at about half of yielding strain to failure. The diagonal reinforcement in the CCB specimen yielded in tension during $1.5 \%$ chord rotation. Even after the tensile yielding of diagonal reinforcements, CCB specimen could exhibit a stable behaviour without the deterioration in strength because transverse reinforcement for full section confinement was effective to delay the buckling of diagonal bars.

In SFRCCB specimen, diagonal reinforcements in tension yielded during the loading of $1.0 \%$ chord rotation. Then tensile strains increased up to failure. Compressive strains in diagonal bars increased sharply as opposite to compressive strains in the CCB specimen. At $2.0 \%$ chord rotation, diagonal reinforcements in compression were buckled. From these results, it is shown that steel fibre volume, which satisfied the flexural performance criteria stipulated in ACI 318-08 S5.6.6, is not enough to confine the diagonal reinforcement in the short coupling beams with $l_{n} / h$ of less than 2.0 . 


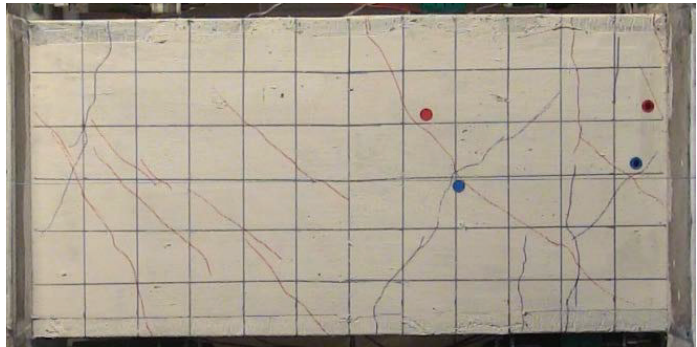

Chord rotation; $0.5 \%$

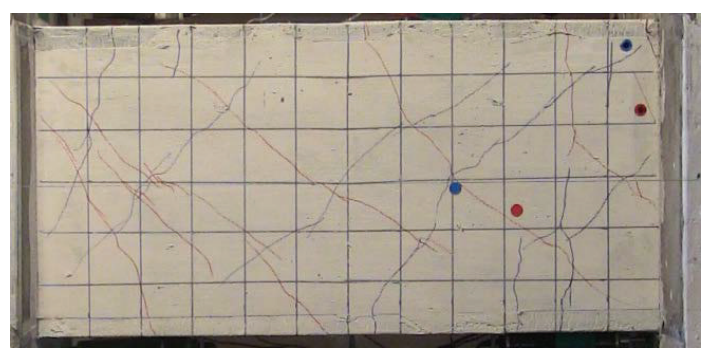

Chord rotation; $1.0 \%$

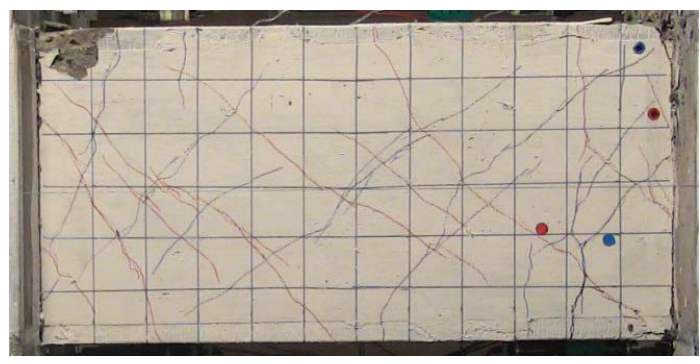

Chord rotation; $2.5 \%$

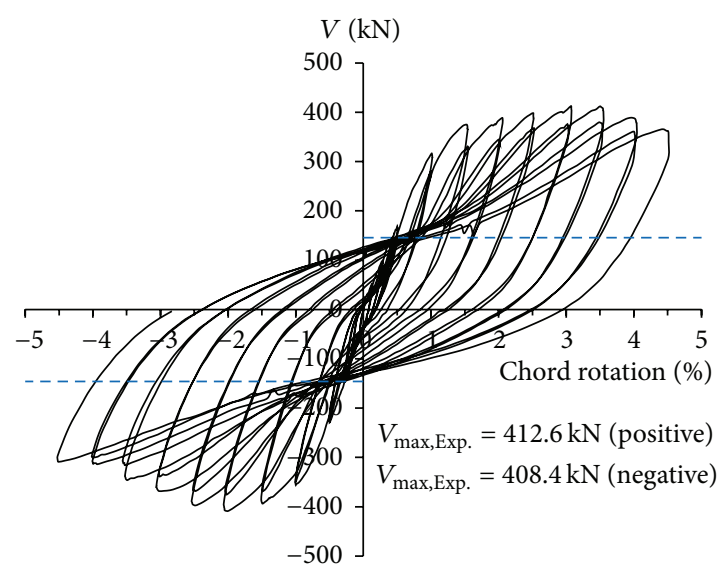

- - $V_{n, \mathrm{ACI}}=2 A_{v d} f_{y} \sin \alpha$

$=145.65 \mathrm{kN}$

(a) CCB specimen

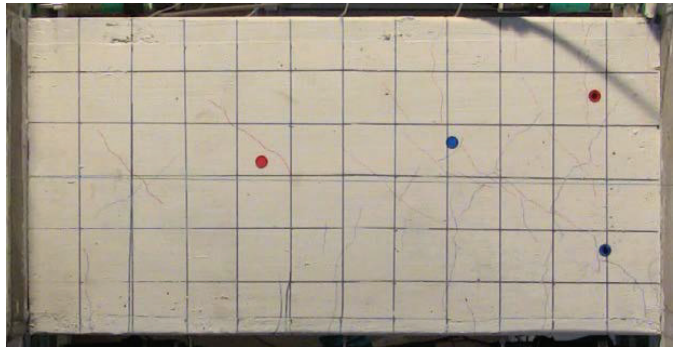

Chord rotation; $0.5 \%$

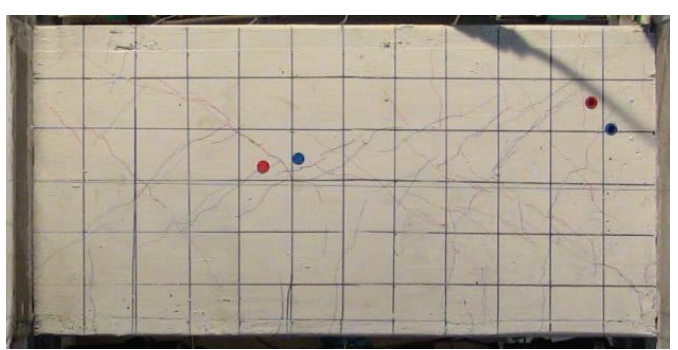

Chord rotation; $1.0 \%$

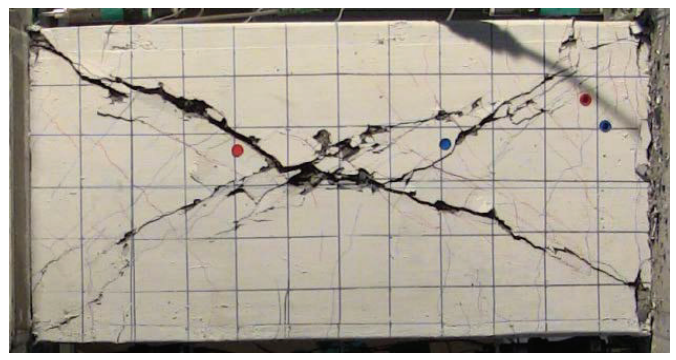

Chord rotation; $2.5 \%$

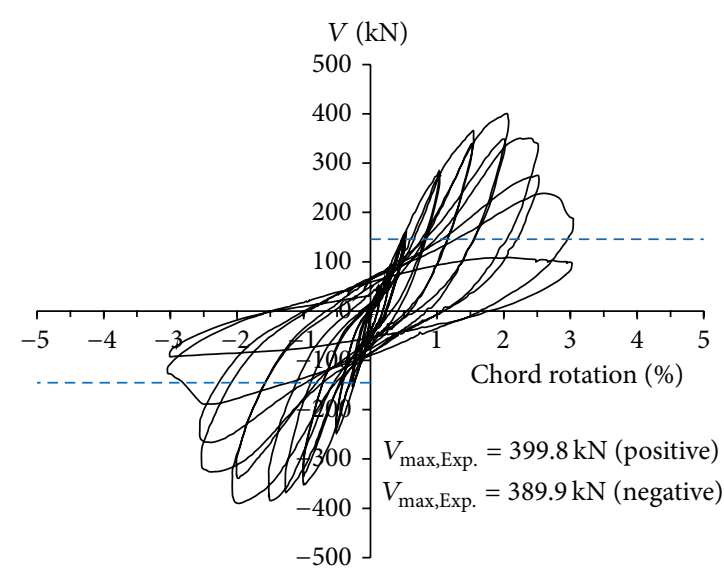

- - $V_{n, \mathrm{ACI}}=2 A_{v d} f_{y} \sin \alpha$

$=145.65 \mathrm{kN}$

(b) SFRCCB specimen

FIGURE 6: Cracking procedure and hysteretic behaviour of coupling beam specimens. 


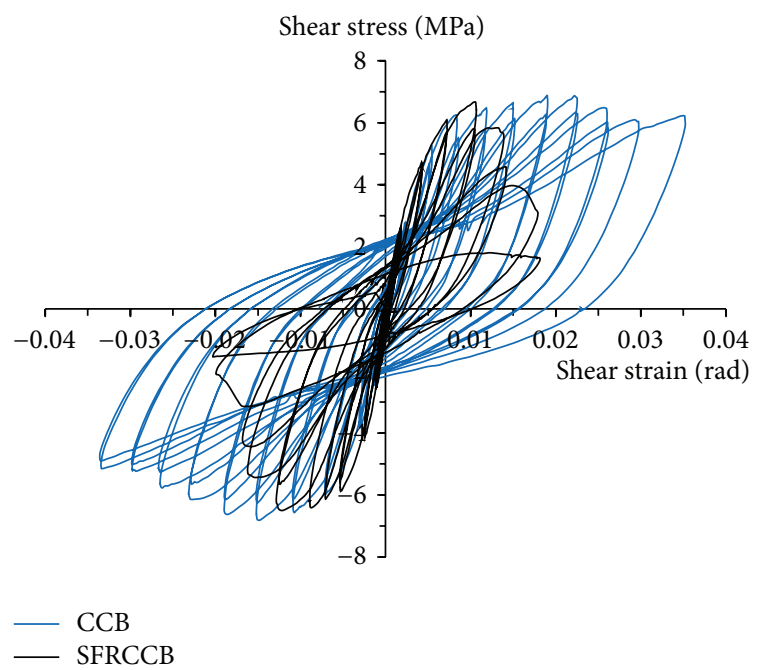

(a) Shear stress-strain responses

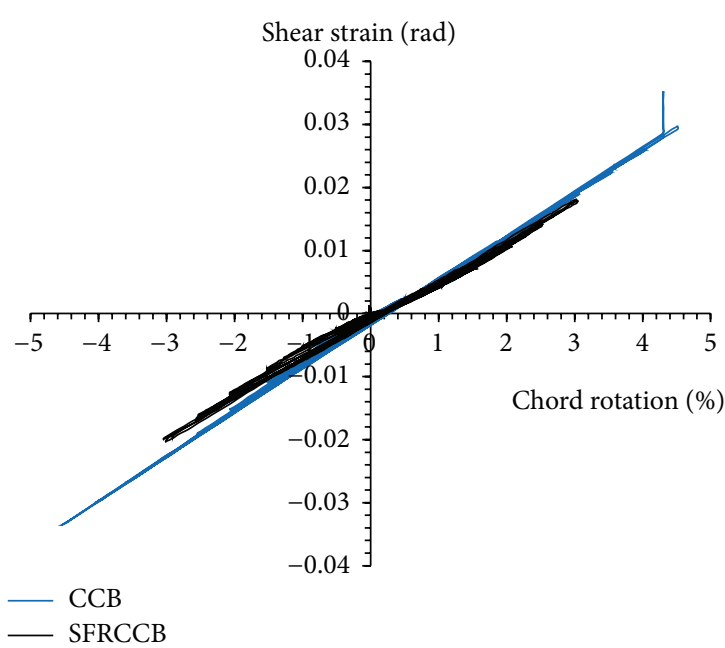

(b) Shear strain and chord rotation relation

FIGURE 7: Average shear stress versus shear strain responses for coupling beam specimens.

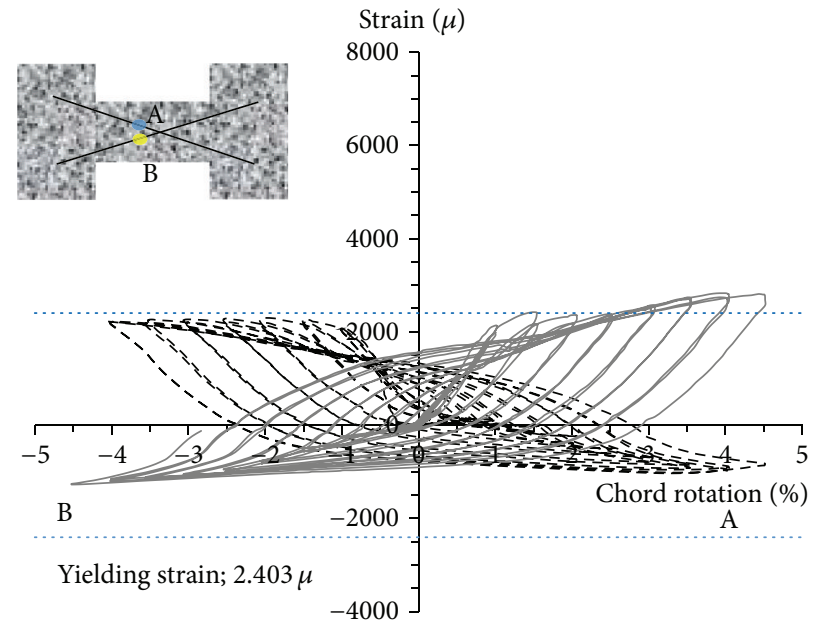

(a) CCB specimen

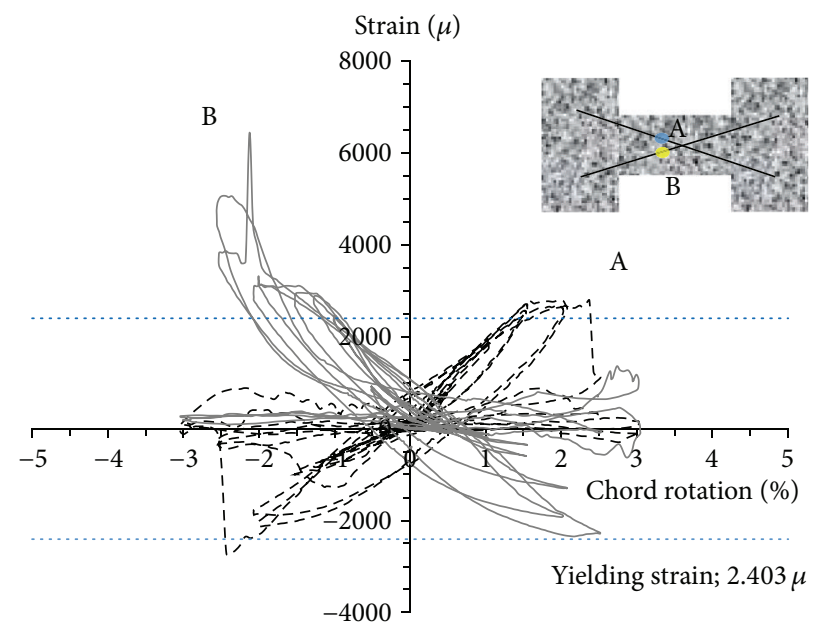

(b) SFRCCB specimen

FIGURE 8: Strain behaviours of diagonal reinforcements in the coupling beams.

3.7. Stiffness Degradation and Energy Dissipation Characteristics. The stiffness of both coupling beams was evaluated in terms of the secant stiffness values obtained from peakto-peak displacement for each hysteretic loop. As can be seen from load versus chord rotation loops, the stiffness decreased with an increase in the chord rotation. The stiffness degradation decreased as the chord rotation increased. The secant stiffness was normalised with respect to the initial secant stiffness to evaluate the stiffness retention capacity of the coupling beam specimens. The energy dissipation capacity of the coupling beam was defined as the area enclosed by the load versus chord rotation loops.

Figures 9(a) and 9(b) show the stiffness decay and cumulative energy dissipation capacity versus chord rotation for both coupling beam specimens, respectively. In Figure 8, it can be seen that up to $2.0 \%$ chord rotation, the stiffness retention and energy dissipation capacities of SFRCCB specimen showed a similar trend compared with those of CCB specimen. Based on these results, it can be concluded that the addition of $1.5 \%$ steel fibre content into diagonally reinforced short coupling beams instead of transverse reinforcement for full section confinement was equivalently effective to retain stiffness and improve the energy dissipation capacity up to $2.0 \%$ chord rotation.

\section{Summary and Conclusions}

Based on the test results of high-performance steel fibre reinforced concrete (HP-SFRC) prismatic specimens, conventional concrete, and HP-SFRC short coupling beams with diagonal reinforcements, the following conclusions can be drawn: 


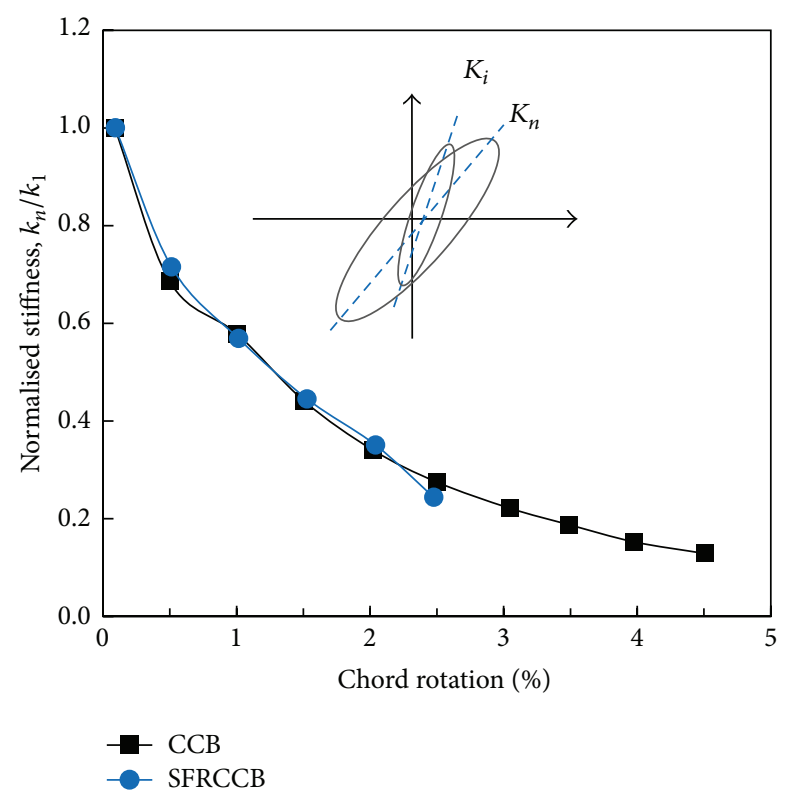

(a) Stiffness degradation

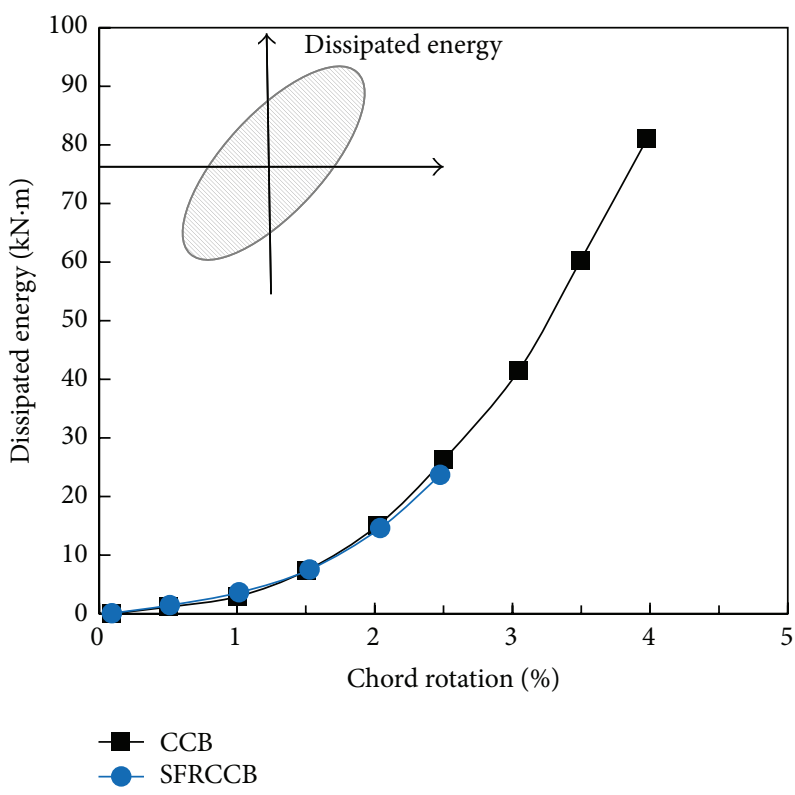

(b) Cumulative energy dissipation capacity

FIGURE 9: Stiffness retention and energy dissipation characteristics.

(1) For all HP-SFRC mixtures mixed in this study, there was no problem in mixing and casting up to hookedend steel fibre volume fraction of $1.5 \%$. Fibres were distributed uniformly in the concrete matrix. However, increasing fibre content increased the amount of entrapped air and reduced the slump values of the fresh HP-SFRC.

(2) The presence of hooked-end steel fibres had little effect on the compressive strength of HP-SFRC with specific compressive strength of 60 and $100 \mathrm{MPa}$. The modulus of rupture in the HP-SFRC slightly improved with increasing fibre volume fractions. The addition of $1.5 \%$ steel fibres to the $60 \mathrm{MPa}$ and $100 \mathrm{MPa}$ HPC caused a maximum increase of $42.3 \%$ and $30.0 \%$ compared with the modulus of rupture of HPC without steel fibres, respectively.

(3) The postpeak behaviour of HPC was very improved with the incorporation of hooked-end steel fibre. For HP-SFRCs, the flexural toughness values calculated in accordance with the ASTM C 1609 procedure increased as steel fibre volume fraction increased. Hooked-end steel fibre volume fractions of $1.2 \%$ and $1.5 \%$ in the 60 and $100 \mathrm{MPa}$ HPCs mixed in this study are sufficient to satisfy the flexural performance criteria specified in the ACI 318-08 S5.6.6 allowing the replacement of minimum shear reinforcement with deformed steel fibres.

(4) The pattern and width of cracks developed in diagonally reinforced concrete coupling beam replaced all the transverse reinforcements with $1.5 \%$ hookedend steel fibres under cyclic shear loadings, similar to those of the corresponding nonfibrous coupling beam with transverse reinforcements up to $1.5 \%$ chord rotation.

(5) Due to crack-bridging action by steel fibre, more fine cracks distributed over the SFRC coupling beam. Fine cracks lead to the reduction of shear distortion. Steel fibre in the short coupling beam with aspect ratio of 2.0 is effective to inhibit the crack development and decrease the increasing rate of shear strain.

(6) The presence of $1.5 \%$ fibre content in the $60 \mathrm{MPa}$ highstrength concrete coupling beam with diagonal bar groups without transverse reinforcements specified in the seismic design provisions for coupling beams in the ACI 318-08 is sufficient to develop the equivalent shear resistance of conventional coupling beams with diagonal reinforcement groups confined transversely. To achieve a comparable level of ductility prior to shear failure of the diagonally reinforced short coupling beams, partial replacement of transverse reinforcements with steel fibre is necessary.

\section{Conflict of Interests}

The authors declare that there is no conflict of interests regarding the publication of this paper.

\section{Acknowledgments}

This research was supported by a grant (13SCIPA02) from Smart Civil Infrastructure Research Program funded by Ministry of Land, Infrastructure, and Transport (MOLIT) of Korea government and Korea Agency for Infrastructure Technology Advancement (KAIA). 


\section{References}

[1] P. R. Tadepalli, Y. L. Mo, and T. T. C. Hsu, "Mechanical properties of steel fibre concrete," Magazine of Concrete Research, vol. 65, no. 8, pp. 462-474, 2013.

[2] R. Narayanan and I. Y. S. Darwish, "Use of steel fibers as shear reinforcement," ACI Structural Journal, vol. 84, no. 3, pp. 216227, 1987.

[3] P. Casanova and P. Rossi, "Can steel fibers replace transverse reinforcements in reinforced concrete beams?" ACI Materials Journal, vol. 94, no. 5, pp. 341-351, 1997.

[4] C. Cucchiara, L. La Mendola, and M. Papia, "Effectiveness of stirrups and steel fibres as shear reinforcement," Cement and Concrete Composites, vol. 26, no. 7, pp. 777-786, 2004.

[5] S. A. Ashour, G. S. Hasanain, and F. F. Wafa, "Shear behavior of high-strength fiber reinforced concrete beams," ACI Structural Journal, vol. 89, no. 2, pp. 176-184, 1992.

[6] K. H. Tan, K. Murugappan, and P. Paramasivam, "Shear behavior of steel fiber reinforced concrete beams," ACI Structural Journal, vol. 90, no. 1, pp. 3-11, 1993.

[7] R. N. Swamy, R. Jones, and A. T. P. Chiam, "Influence of steel fibers on the shear resistance of lightweight concrete I-beams," ACI Structural Journal, vol. 90, no. 1, pp. 103-114, 1993.

[8] Y. K. Kwak, M. O. Eberhard, W. S. Kim, and J. Kim, "Shear strength of steel fiber reinforced concrete beams without stirrups," ACI Structural Journal, vol. 99, no. 4, pp. 530-538, 2002.

[9] V. C. Li, R. Ward, and A. M. Hamza, "Steel and synthetic fibers as shear reinforcement," ACI Materials Journal, vol. 89, no. 5, pp. 499-508, 1992.

[10] S. Furlan Jr. and J. B. de Hanai, "Shear behaviour of fiber reinforced concrete beams," Cement and Concrete Composites, vol. 19, no. 4, pp. 359-366, 1997.

[11] D. H. Lim and B. H. Oh, "Experimental and theoretical investigation on the shear of steel fibre reinforced concrete beams," Engineering Structures, vol. 21, no. 10, pp. 937-944, 1999.

[12] G. Batson, C. Ball, L. Bailey, E. Landers, and J. Hooks, "Flexural fatigue strength of steel fiber reinforced concrete beams," ACI Journal Proceedings, vol. 69, no. 11, pp. 673-677, 1972.

[13] R. N. Swamy and H. M. Bahia, "The effectiveness of steel fibers as shear reinforcement," Concrete International, vol. 7, no. 3, pp. 35-40, 1985.

[14] C. E. Chalioris and C. G. Karayannis, "Effectiveness of the use of steel fibres on the torsional behaviour of flanged concrete beams," Cement and Concrete Composites, vol. 31, no. 5, pp. 331341, 2009.

[15] Z. You, Y. Ding, and C. Niederegger, "Replacing stirrups of selfcompacting concrete beams with steel fibers," Transactions of Tianjin University, vol. 16, no. 6, pp. 411-416, 2010.

[16] F. Minelli and G. A. Plizzari, "On the effectiveness of steel fibers as shear reinforcement," ACI Structural Journal, vol. 110, no. 3, pp. 379-390, 2013.

[17] K. Jain and B. Singh, "Steel fibres as minimum shear reinforcement in reinforced concrete beams," Magazine of Concrete Research, vol. 65, no. 7, pp. 430-440, 2013.

[18] K. Jain and B. Singh, "Deformed steel fibres as minimum shear reinforcementa comparative appraisal," Magazine of Concrete Research, vol. 66, no. 22, pp. 1170-1182, 2014.

[19] C. E. Chalioris, "Steel fibrous RC beams subjected to cyclic deformations under predominant shear," Engineering Structures, vol. 49, pp. 104-118, 2013.
[20] ACI Committee 318, Building Code Requirements for Structural Concrete (ACI 318-08) and Commentary, American Concrete Institute, Farmington Hills, Mich, USA, 2008.

[21] M. Z. Bayasi and P. Soroushian, "Effect of steel fiber reinforcement on fresh mix properties of concrete," ACI Materials Journal, vol. 89, no. 4, pp. 369-374, 1992.

[22] Ö. Eren and T. Çelik, "Effect of silica fume and steel fibers on some properties of high-strength concrete," Construction and Building Materials, vol. 11, no. 7-8, pp. 373-382, 1997.

[23] P. Balaguru and H. Najm, "High-performance fiber-reinforced concrete mixture proportions with high fiber volume fractions," ACI Materials Journal, vol. 101, no. 4, pp. 281-286, 2004.

[24] I. Mehdipour, N. A. Libre, M. Shekarchi, and M. Khanjani, "Effect of workability characteristics on the hardened performance of FRSCCMs," Construction and Building Materials, vol. 40, pp. 611-621, 2013.

[25] T. Paulay, "Coupling beams of reinforced concrete shear walls," Journal of the Structural Division, vol. 97, no. 3, pp. 843-862, 1971.

[26] D. Naish, Testing and modeling of reinforced concrete coupling beams [Ph.D. thesis], University of California, Los Angeles, Los Angeles, Calif, USA, 2010.

[27] D. R. Sahoo and A. Sharma, "Effect of steel fiber content on behavior of concrete beams with and without stirrups," $A C I$ Structural Journal, vol. 111, no. 5, pp. 1157-1166, 2014. 

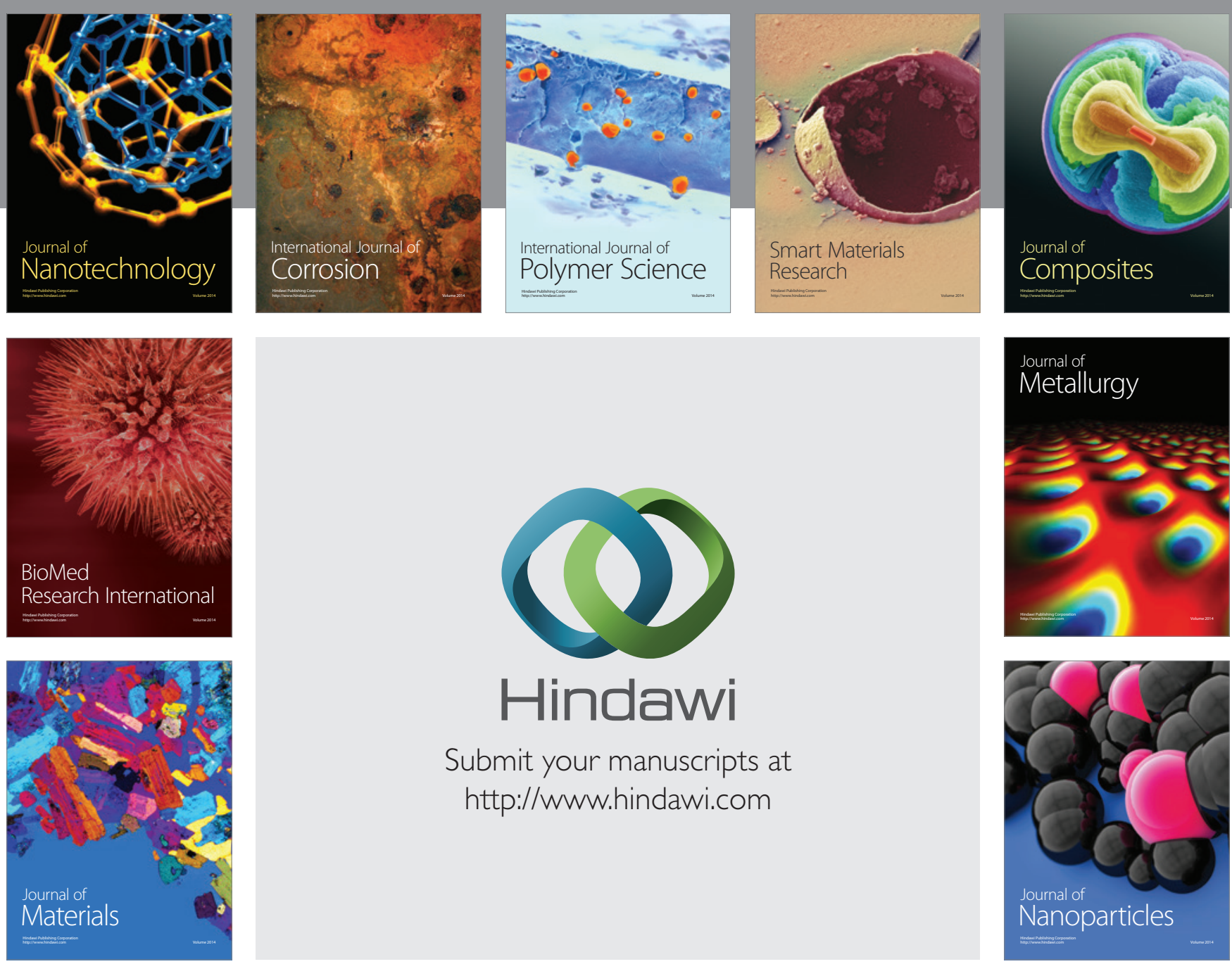

Submit your manuscripts at http://www.hindawi.com
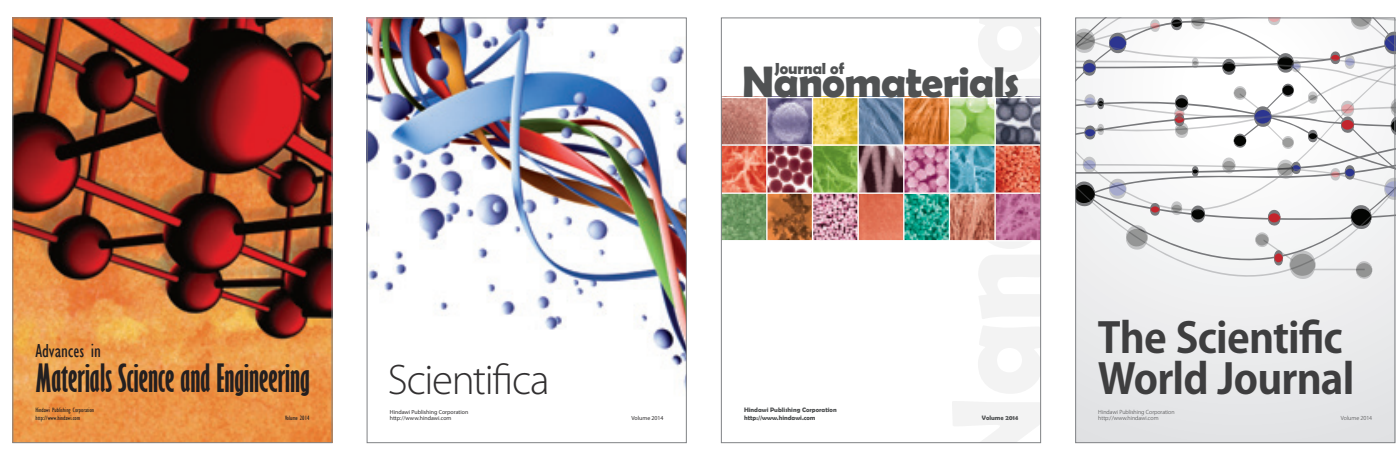

\section{The Scientific World Journal}
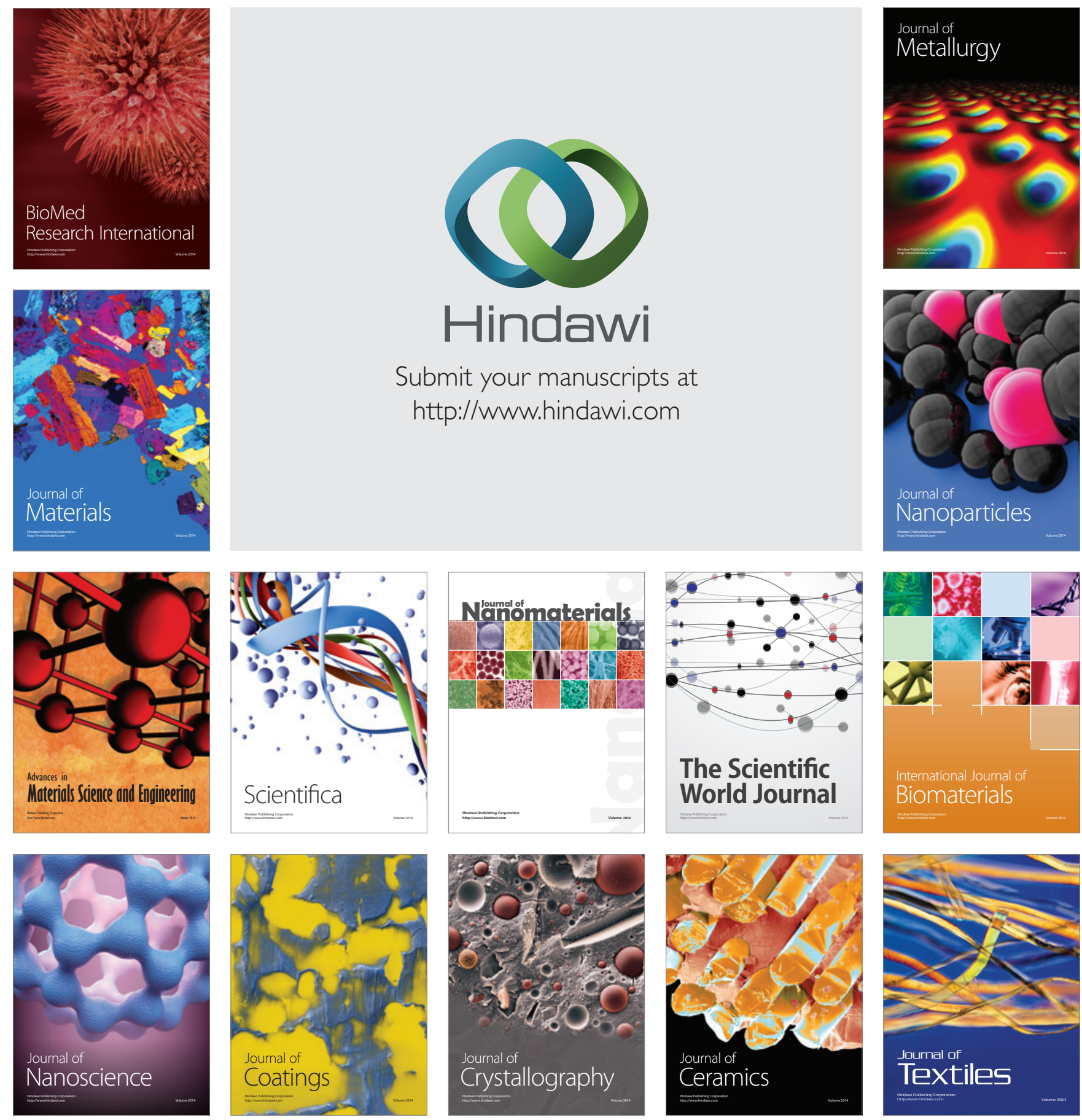